\title{
Great Lakes Water Levels: Decomposing Time Series for Attribution
}

\author{
Pietrafesa $\mathrm{LJ}^{1,3 *}$, Shaowu Bao1, Huang NE², Gayes PT'1, Yan $\mathrm{T}^{1}$ and Slattery MP1
}

${ }^{1}$ Coastal Carolina University, School of Coastal and Marine Systems Science Conway, South Carolina 29528, USA

${ }^{2}$ National Central University, Research Center for Adaptive Data Analysis Zhongli, Taiwan 32001, China

${ }^{3}$ North Carolina State University, College of Science Raleigh, North Carolina, USA

\begin{abstract}
Great Lakes water levels have been trending downwards throughout the $20^{\text {th }}$ and into the $21^{\text {st }}$ Centuries. Potential causes are numerous. There have been dredging and water diversion projects over the last 110 years, increasing demand for fresh water consumption from a rising population, and considerable variations in environmental factors (rainfall, snowfall, air temperature and wind), all causal in nature. A thorough assessment of United States federal agency and laboratory data archives of time series of winds, air temperatures, rainfall and snowfall, and water level data, reveals that falling lake levels can be linked to rising air temperatures. Non-uniform, post-glacial, isostatic adjustments of the entire Great Lakes region has further complicated the system as land mass tilting causes localized uplift or subsidence that has also altered relative water levels. A mathematical decomposition of the various data sets and accessory calculations strongly indicate regional atmospheric temperature increases over the entire $20^{\text {th }}$ century and the early $21^{\text {st }}$ century resulting in increased evaporation, is the dominant driving factor in the continued downward trend of water levels in the Great Lakes. Moreover, a high degree of correlation was discovered in comparing water level in the Great Lakes with the comparable temporal variability and record length trends evident both the Global (Land and Ocean) Surface Temperature Anomaly time series and the Atlantic Multi-Decadal Oscillation. It is of note that there have been several water level events since 2013 from which the long term losses of fresh water have undergone a change and the lakes have gained fresh water. This received a great deal of attention in both the public press and a scientific newsletter and shows that there is a danger in only dealing with a small portion, 2 years, of a 120 year climate record.
\end{abstract}

Keywords: Climate change; Great lakes water level; Atmospheric warming; Hydrographic budget; Isostatic rebound; Hilbert-Huang transformation; Ensemble empirical modal decomposition

\section{Introduction}

The Great Lakes Basin (Figure 1) is home to approximately 40 million people. The combined 4,500 miles of United States (U.S) Great Lakes coastline is greater than the combined length of coastline for U.S. coasts in Atlantic, Gulf and Pacific and provides important commercial, residential and recreational uses [1] and for hydropower, agricultural irrigation and fisheries [2], within estimated net worth in the hundreds of billions of dollars annually [3]. To meet all of the competing demands on the water resources, the Great Lakes have been significantly altered by engineered changes to the inter-lake water flows. The U.S. Army Corps of Engineers (ACE) dredged the St. Clair and Detroit Rivers for reasons of improving navigation. These projects deepened the channel by removing sand and gravel from the river bed. The St. Clair/ Detroit River system deepening occurred from 1910 to1923 (the $6.7 \mathrm{~m}$ deepening project); from 1933 to 1936 (the $7.5 \mathrm{~m}$ deepening project); and from 1958 to 1962 (the $8.2 \mathrm{~m}$ deepening project). The only dredging that has occurred since has been maintenance dredging. However, there have also been diversions of water, mainly for municipal and industrial water consumption.

The water resource needs for the Great Lakes are very sensitive to lower water levels. To minimize impacts, various water deepening and diversion projects were designed to result in small variability in water level to counteract any abnormally low water levels that could impact the availability of Great Lakes water resources for traditional uses, especially shipping. Among the myriad of uncertainties, the most important, looming, area of concern is with respect to the impact global climate change will have on water levels. To attempt to better manage the water system, diversions have been reduced to help restore traditional flows in many cases to avoid hitting critical depth thresholds in Lake Levels in response to diversifying demands. We will investigate environmental factors that could influence Great Lakes water levels over multiple temporal scales of variability via the use of federal archives of time series of data to conduct our analyses.

\section{Background}

In 1900, the City of Chicago reversed the flow of the Chicago River, a diversion, so that instead of flowing into Lake Michigan, the river flowed out of Lake Michigan toward the Mississippi River system. Following decades of negotiations, the eight Great Lakes States (the GLS) entered into a Consent Decree in 1967 regulating the diversion of Lake Michigan water into the Chicago River. The decree states that the State of Illinois may not divert more than $3,200 \mathrm{ft}^{3} /$ second $\left(90.614 \mathrm{~m}^{3} /\right.$ second) from Lake Michigan for navigation, domestic or sanitary uses.

At the rate of withdrawal of fresh water from Lake Michigan, and given the lake's surface area of approximately $57,955 \mathrm{Km}^{2}$, that withdrawal would result in an annual drop of $\sim 4.2 \mathrm{~cm}$ per year. As this has been occurring since at least 1967, a period of 46 years up through 2012 , this would have amounted to a net drop of $192.8 \mathrm{~cm}$ in lake level. At face value, one could then assume the low water level culprit to be water diversion. However, not just outputs should be considered and

${ }^{*}$ Corresponding author: Pietrafesa LJ, Coastal Carolina University, School of Coastal and Marine Systems Science Conway, South Carolina 29528 and North Carolina State University, College of Science Raleigh, North Carolina, USA, Tel: +7049107047; E-mail: ljpietra@ncsu.edu

Received January 19, 2016; Accepted January 25, 2016; Published January 30 2016

Citation: Pietrafesa LJ, Shaowu Bao, Huang NE, Gayes PT, Yan T, et al. (2016) Great Lakes Water Levels: Decomposing Time Series for Attribution. J Climatol Weather Forecasting 4: 153. doi:10.4172/2332-2594.1000153

Copyright: (c) 2016 Pietrafesa LJ, et al. This is an open-access article distributed under the terms of the Creative Commons Attribution License, which permits unrestricted use, distribution, and reproduction in any medium, provided the original author and source are credited. 


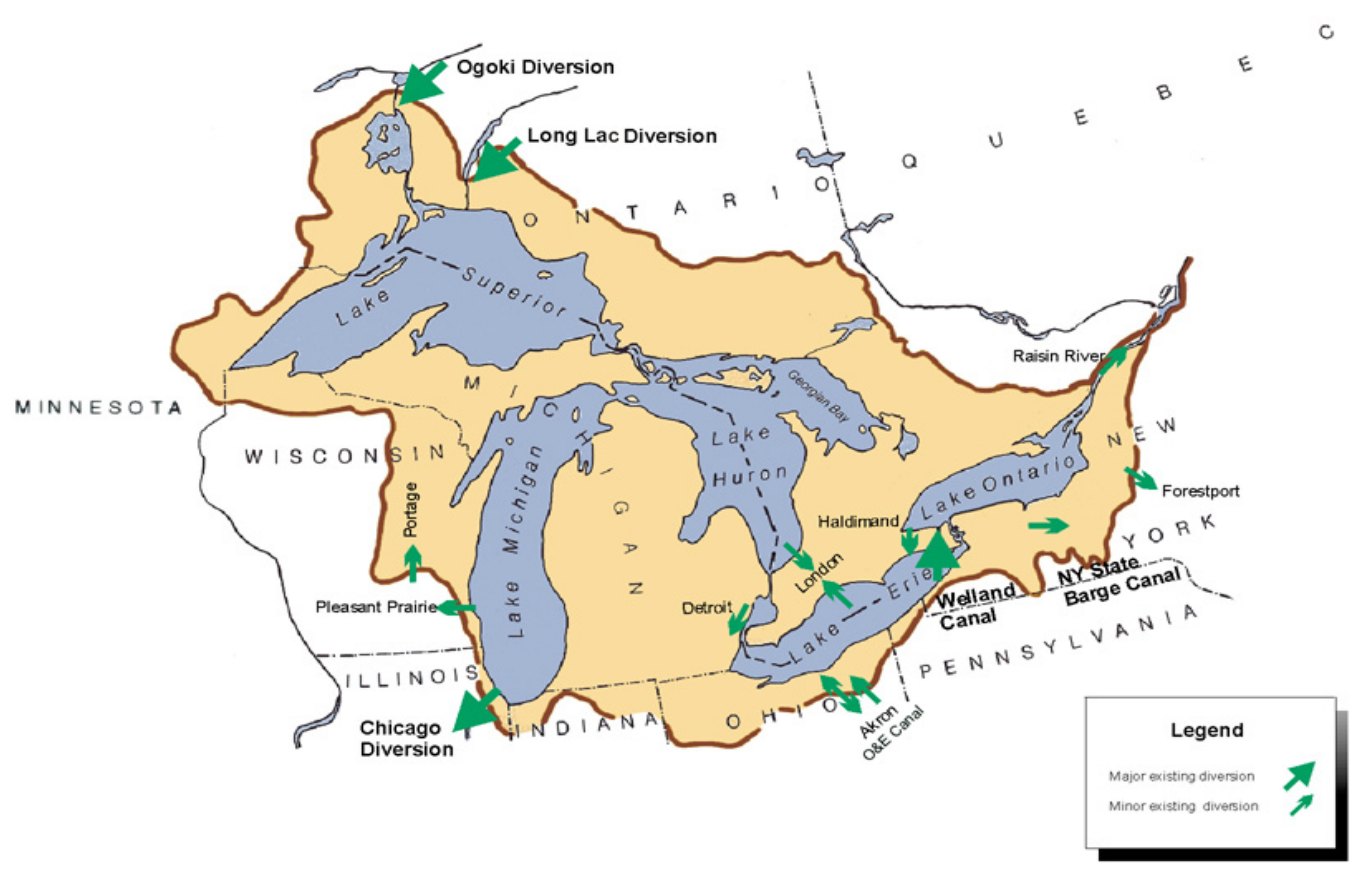

Figure 1: The Great Lakes region and water diversions.

we have not yet accounted for potential offsetting inputs of fresh water into the system. There are the diversions of water from Canada into Lake Superior of $141 \mathrm{~m}^{3} /$ second via the Long Lac and Ogoki Diversions and this additional water drain into Lake Michigan. Additionally, the climatology of rainfall for the Lake Michigan water basin was studied by Changnon [4] and reported to be $75.2 \mathrm{~cm} / \mathrm{yr}$. This input along with the Canadian diversions is more than sufficient to cover the losses due to water diversion of Lake Michigan. It's also estimated that only $5 \%$ of the withdrawn water is consumed, while $95 \%$ is returned to the lakes.

\section{Prior Work}

Much of the work to date in looking into Great Lakes water level drops has been focused on the potential role that climate change has had, is having and may have and has relied on prognostications from a suite of General Circulation Models (GCMs). The bulk of the literature indicates that an expected drop in water level could result from increasing temperatures and associated evaporation, but results are still inconclusive when the full body of work is examined.

While GCMs are very useful for long-term predictions of future trends, several weaknesses were identified in several assessments of model results. The GCMs demonstrated significant differences given the multiple, tested GCMs [2] and the notion that variability in the natural climate system is influencing model output could be inferred from the conclusions of MacKay [3]. Lofgren et al. [5] note that there have been results of both lower and higher water levels under varying climate change based model results. Some of the uncertainty seems linked to the unknowns surrounding the role of evapotranspiration [6]. A larger component of variability is likely linked to the fact there is no accepted evaluation strategy for determining the quality of skill for prediction among the GCMs [7].

In our study, we do not propose to replace the important use of GCMs in attempting to evaluate and predict regional trends in water level, but rather we will examine environmental data archives, and employ a specific empirical mathematical method that allows for a trend analysis, along with an investigation of internal modes of variability that are buried within the data sets; all of which are inherently nonstationary and non-linear.

\section{Methods and Terms}

In order to fully explore the applicability of the methods applied in this study, it is first necessary to address the definition of several commonly used terms. While the terms "trend" and "normal" seem inherently clear, when discussing non-stationary, non-linear data sets, the terms can be unclear and thus should be clarified for our analyses to follow. Typical methods of establishing trends through time series of either NS or NL data are ineffective. If the entire data set is used to define the trend-line, the annualized variability is subject to a variety of shorter time scale fluctuations that aren't captured in the trend. Moreover, without knowledge of the inherent time scales of variability buried within the suite of data, it's not reasonable to conduct "running" or "boxcar" averaging. However, the development of the Empirical Modal Decomposition (EMD) methodology [8] was based on the development of the Hilbert-Huang Transform (HHT) provided a mathematical platform as the only data decomposition methodology that allows for proper treatment of NS and NL data. Neither Fourier analysis nor Wavelet-Morlet Analysis can properly transform and preserve the content of NS and NL time series as has been thoroughly discussed and proven by [8]. Employing the HHT and EMD reveals the internal cycles of variability or more formally, the Intrinsic Mode Functions (IMFs), buried within continuous time series data sets. It is of note here that EMD does not utilize a prescribed basis function and is "adaptive" to the entirety of the data set. That study indicated that the overall bent of the data in a time series, being internal and intrinsic to the data set, could only be determined via the employment of a method that was adaptive to the entirety of the data set and is the "gravest mode" buried within the data set. Subsequently, Wu [9] presented the development of the "ensemble" EMD (or EEMD) which 
introduced "white noise" into the mathematical methodology as a statistical conditioning phase.

In $\mathrm{Wu}$ et al. [10] it was argued that the multiple, myriad of definitions of a "trend" were not based on a sound mathematical basis and thus there was no mathematically defensible definition of a trend in a data set. Thus, the method that we will employ in our analyses is based on a simple, logical definition of the overall "trend" of any data time series, which includes non-stationary and non-linear time series. Also, we will employ the HHT and EEMD mathematical methodologies. As such, the gravest modes or trends that we will compute can have at most one inflection point. So, the trend of a data set can go up in slope or down in slope or up and down in slope or down and up in slope. There is also the NOAA based concept and definition of a "normal" of a time series of data; which we should address as our data sets are NOAA derived.

A "normal" of environmental data is defined by NOAA (NCEI) as a 30 year average of the continuous time series of an environmental data set. As such it is one value computed and updated every new decade ending with a zero; such as $1790-1820$ and then $1800-1830$, and so on. This is what we will refer to as a "static normal". However in our text, we will introduce the concept of a "dynamic normal", which will be based on the before discussed definition of a "trend". We see no physical reason that a "normal" should be defined as a 30- year average and be locked in as a single static number. We believe that the description of the "base modality" of a changing environment, as represented by a state variable, should represent how that variable changes cumulatively over the length of the period being measured, i.e., the time series of the variable. We define our "dynamic normal" as a moving value, by definition the "trend", of a specific environmental time series including all of the data collected in the total time series.

\section{Data Sources and Treatment}

Our sources of data for the analysis are the NCEI and NCEP/ NCAR-RP, the latter of which was initiated to produce new atmospheric analyses using historical data (1948 onwards) and to the current atmospheric state (Climate Data Assimilation System, CDAS). The location and period of the reanalyzed data are: $42.67^{\circ} \mathrm{N} 87.0^{\circ} \mathrm{W}$ (near the NOAA National Data Buoy Center (NDBC) buoy \#45007) from January 1949 to September 2013. As regards water temperatures below zero, Dr. Wesley Ebisuzaki, NOAA revealed (via personal communication) that: "On the model grid (high resolution Gaussian grid), the grid point should be either land or water/ice. When there is no ice, the TMPsfc should be the SST. When the water is ice-covered, then TMPsfc should be the top of the ice layer (skin temperature)". Therefore in the calculation of the EEMD modes, the water temperature is truncated at zero.

In our study of water level variability in the Great Lakes, we will utilize several data sets for multiple strategies. The first strategy will be to compare several key data sets across all five Great Lakes. A 43year data set, selected for completeness from 1971-2012, shows the relative conformity in water level variability across the five Great Lakes. These records will be presented for comparative purposes only. The data that we will utilize for the lake inter-comparisons include time series of water level, rainfall, snowfall, air temperature and wind speed. The second will be to focus on one Great Lake, Lake Michigan, and maximize those data sets in time to reveal the internal cycles of variability and overall trends of all environmental data considered. For purposes of completeness but also economy of scale, we focus on Lake Michigan as being representative of all of the Great Lakes for the longer time series. The longer time series from Lake Michigan dates from 1895 to 2013 for rainfall (from Division 6 in Wisconsin), 1903 to 2013 for water level (from Calumet Harbor, IL), and 1928 to 2013 for air temperature, snowfall and winds (From Chicago's Midway Airport). In order to look at the data more thoroughly, we examine the annual values by month over all years of observations of snow accumulation, rainfall, air temperature, winds and water level for the Lake Michigan domain. In an effort to remove biasing from heat island effects, we will examine contemporaneous air temperature data from Aurora, IL (approximately $59 \mathrm{Km}$ southwest of Chicago) in addition to the Chicago, IL air temperature record.

For lake inter-comparison purposes the water level data are monthly from each of the lakes and were selected based upon the completeness of the data sets. The rainfall data are monthly and from: a) Lake Superior - Minnesota division 3; b) Lake Michigan - Wisconsin division 6; c) Lake Huron - Michigan division 7; d) Lake Erie - Ohio division 3; and e) Lake Ontario, New York division 9. Vertical snowfall accumulation data for Chicago are utilized in this study. It is of note that the rule of thumb for snow water equivalency is $25.4 \mathrm{~cm}$ of snow amounts to $2.54 \mathrm{~cm}$ of liquid rain. To remove some of the "noise" from the signal, annualized water level and precipitation for each of the lakes are also examined.

Each dataset of potential driving mechanisms will be analyzed using the EEMD methodology with emphasis on exploring possible common modes of variability that allow visual correlation of water level to the environmental factors that can and may drive relative water levels up and down. Additional data to be evaluated will include: drawdown in water level due to diversions; additions from precipitation; isostatic adjustments in the region which will be accounted for through the work of Mainville and Cramer [11]; and evaporative water loss from the Great Lakes using water surface and above water air temperatures, humidity and wind data, all based on the methods of Fairall et al. [12].

Given the volume of each of the Great Lakes, shoreline dredging, typically done to expand marinas, should have little impact on water levels. However, historical channel dredging projects have altered water levels, according to the ACE's John Allis. The Chicago Diversion is by far the largest of the lake diversions. It moves water out of Lake Michigan at a rate of $90.614 \mathrm{~m}^{3} / \mathrm{s}$. Water flows into Lake Superior from the Albany River system in northern Ontario from the cities of Long Lac and Ogoki at a rate of $141.6 \mathrm{~m}^{3} / \mathrm{sec}$. Water levels and inflows and outflows are regulated by the International Joint Commission (IJC), an independent organization established by the United States and Canada. The IJC's regulation plan is to keep lake levels as close to their longterm averages as possible, but they can only work with the water they have. There are also consumptive uses of Great Lakes water [13]. It is of note that most of the water that people use from the Great Lakes is returned to the basin, so the amount of water consumed may be too insignificant to consider when looking at the overall impact on Great Lakes water levels. Guerriero states "We use a lot of water, but most of it is returned. We estimate that the average consumption rate is about 5 percent, but since the 1990s, there has been a decrease in withdrawals because of efficiency and conservation standards". While lake diversions may ultimately play some role in water level changes over time, there is evidence that the impact is minimized by current practices.

\section{Results}

The first data set(s) examined included water level and rainfall data from all five of the Great Lake's basins. High visual correlations 
Citation: Pietrafesa LJ, Shaowu Bao, Huang NE, Gayes PT, Yan T, et al. (2016) Great Lakes Water Levels: Decomposing Time Series for Attribution. J Climatol Weather Forecasting 4: 153. doi:10.4172/2332-2594.1000153

between precipitation and water level would be expected. Some trends appear in both of the data sets displayed in (Figures 2 and 3) with water levels and precipitation lowest in the winter months and highest in the summer months. However, despite the long-term agreement in the climatological seasonal cycle, water levels visually appear to have been dropping over the data record lengths for each of the Great Lakes (though much less pronounced in Ontario), while precipitation has been fairly stable. From the tables of water level versus precipitation (tables are not presented herein) in general there is a nominal $0.161 \mathrm{~cm}$ rise of water level per $1.0 \mathrm{~cm}$ of rainfall.

In Figures 4 and 5, we re-examine the data from Figures 2 and 3 by annualizing water level and rainfall. There is visual consistency in the amplitudes and monthly to seasonal to annual cycles between water levels and also separately between rainfalls from lake to lake

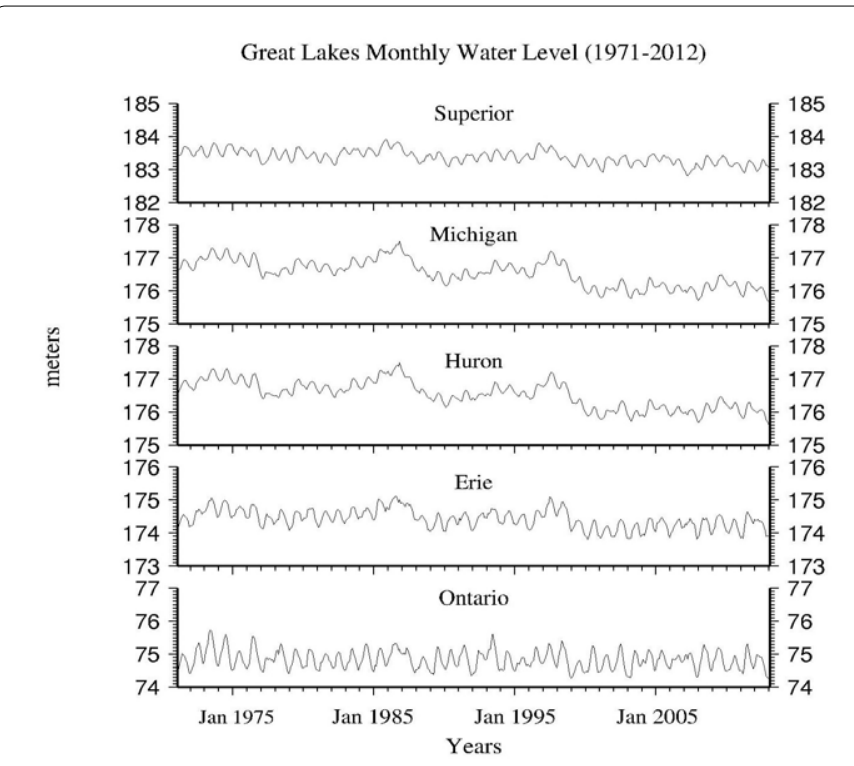

Figure 2: Monthly water level time series of the five Great Lakes, 1971-2012.

Great Lakes Area Monthly Precip (1971-2012)

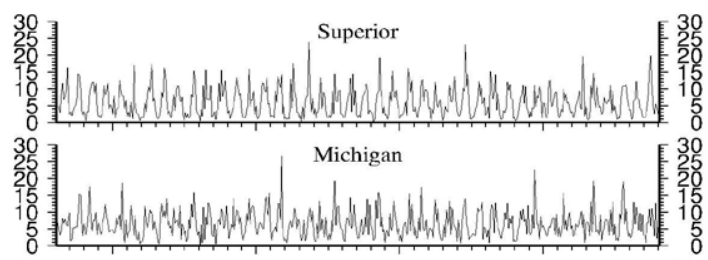

ธี

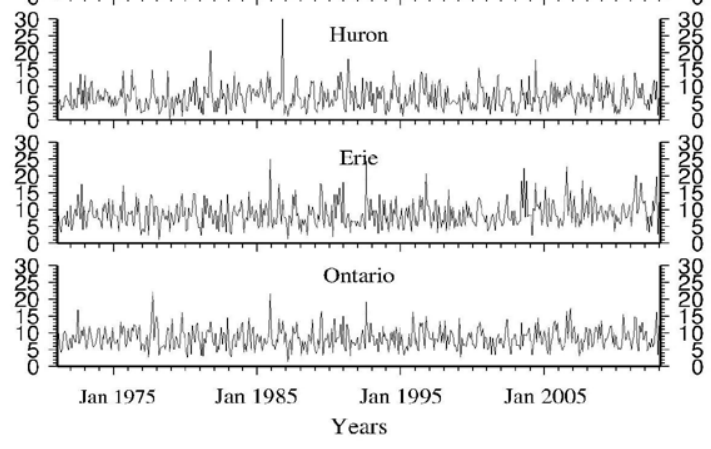

Figure 3: Monthly rainfall data from the five Great Lakes zones, 1971-2012.

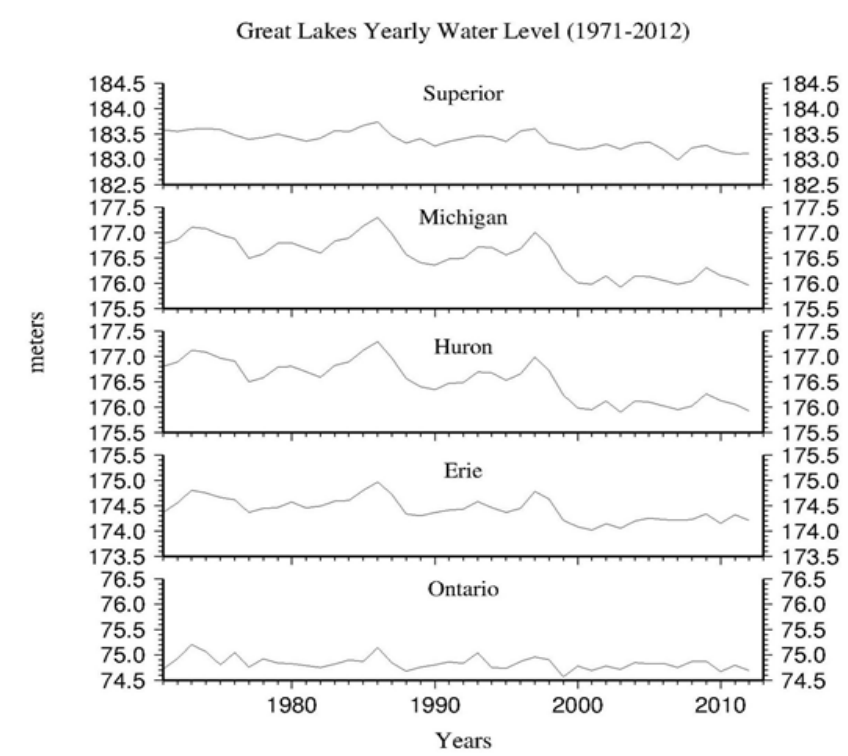

Figure 4: Annualized water levels in each of the five Great Lakes, 1971 2012.

Great Lakes Area Yearly Precip (1971-2012)

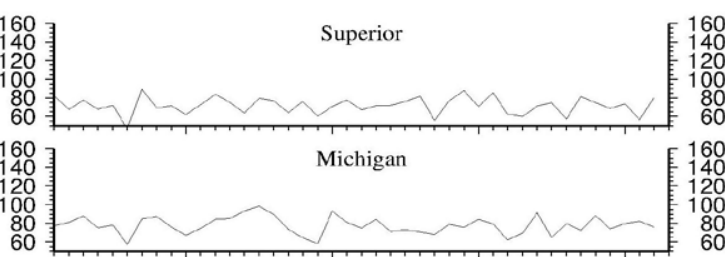

ฐี

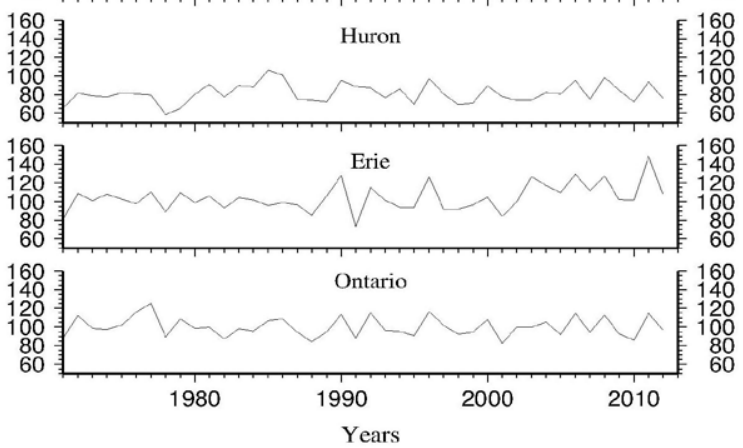

Figure 5: Annualized rainfall in the five Great Lake zones, 1971-2012.

throughout the region. Visually, annualized water levels have dropped over the record lengths. However, though the rainfall time series are busy, the levels of precipitation appear to be overall quite stable, though there are considerable differences across the Great Lakes region. The time series of rainfall and water level are clearly both non-stationary and non-linear and as such are difficult to compare, visually. Rainfall has changed by as much as the extreme of $48 \mathrm{~cm}$ between consecutive years, such as between 1990 and 1991, in Lake Superior, and water levels have varied by as much as the extreme of $50 \mathrm{~cm}$ between consecutive years, such as between 1998 and 1999 in Lakes Superior and Michigan. When considering water level and precipitation, it is clear that the two data sets do not appear to visually depict any easily demonstrable relationships over the 43 -year data set. These facts strongly suggest that 
Citation: Pietrafesa LJ, Shaowu Bao, Huang NE, Gayes PT, Yan T, et al. (2016) Great Lakes Water Levels: Decomposing Time Series for Attribution. J Climatol Weather Forecasting 4: 153. doi:10.4172/2332-2594.1000153

Page 5 of 14

1 or 2 or even 5 years of persistently high (or low) annualized water levels can be a sign of a resurgence (or rapidly increasing losses) of Great Lakes water levels,, but in the grand scheme of water level temporal variability, these are short term changes and the overall trends may still be downward. We will look into this further below.

Figure 6 demonstrates the collective and representative annual averaged values of water level in Calumet Harbor IL, rainfall from Division 6 in Wisconsin, snow coverage of North America and vertical snow accumulations from Chicago's Midway Airport. The annual averages are presented between 1928 and 2013 for purposes of direct inter-comparisons. It is of note that Lake Michigan is approximately $58,000 \mathrm{~km}^{2}$ laterally. So, $107.95 \mathrm{~cm}$ of snow adds an additional $9.8 \mathrm{~cm}$ of water height directly to Lake Michigan and a slightly lesser amount during the spring and summer due to lateral input from drainage from adjacent land.
Of additional note from Figure 6 is that there are some remarkable ranges of differences in water level on an annualized basis. For example, water levels peaked at $176.75 \mathrm{~m}$ in $1931,177.05 \mathrm{~m}$ in 1952, $177.1 \mathrm{~m}$ in $1973,177.3 \mathrm{~m}$ in 1985 and $177.0 \mathrm{~m}$ in 1997 and reached lows of $175.7 \mathrm{~m}$ in 1934 and 1964, 176.0 $\mathrm{m}$ in 1959, 2000, 2008 and 2012, and $175.95 \mathrm{~m}$ in 2003. So there has been up to $1.6 \mathrm{~m}$ in annualized amplitude change of water level over the 110 years of observations. In the meantime snow accumulations have ranged from $24.5 \mathrm{~cm}$ (or $\sim 2.45 \mathrm{~cm}$ of rain) in 1937, 1949 and 2001 to $172.7 \mathrm{~cm}$ (or $\sim 17.3 \mathrm{~cm}$ of rain) in 1951, 177.8 $\mathrm{cm}$ (or $\sim 17.8 \mathrm{~cm}$ of rain) in 1967 and 2000 , and $241.3 \mathrm{~cm}$ (or $\sim 24.1$ $\mathrm{cm}$ of rain) in 1978; a range of $215.9 \mathrm{~cm}$ (or $\sim 21.6 \mathrm{~cm}$ of rain) over 85 years. Rainfall ranged from $49 \mathrm{~cm}$ in 1930 to $98 \mathrm{~cm}$ in 1985. Annual air temperatures have ranged from $33^{\circ} \mathrm{C}$ in 1929 to nearly $55^{\circ} \mathrm{C}$ in 2012 . Annualized winds have ranged from $5.4 \mathrm{~m} / \mathrm{s}$ in 1969 to $3.8 \mathrm{~m} / \mathrm{s}$ in 1980 . Such a widely varying dataset is difficult to assess.

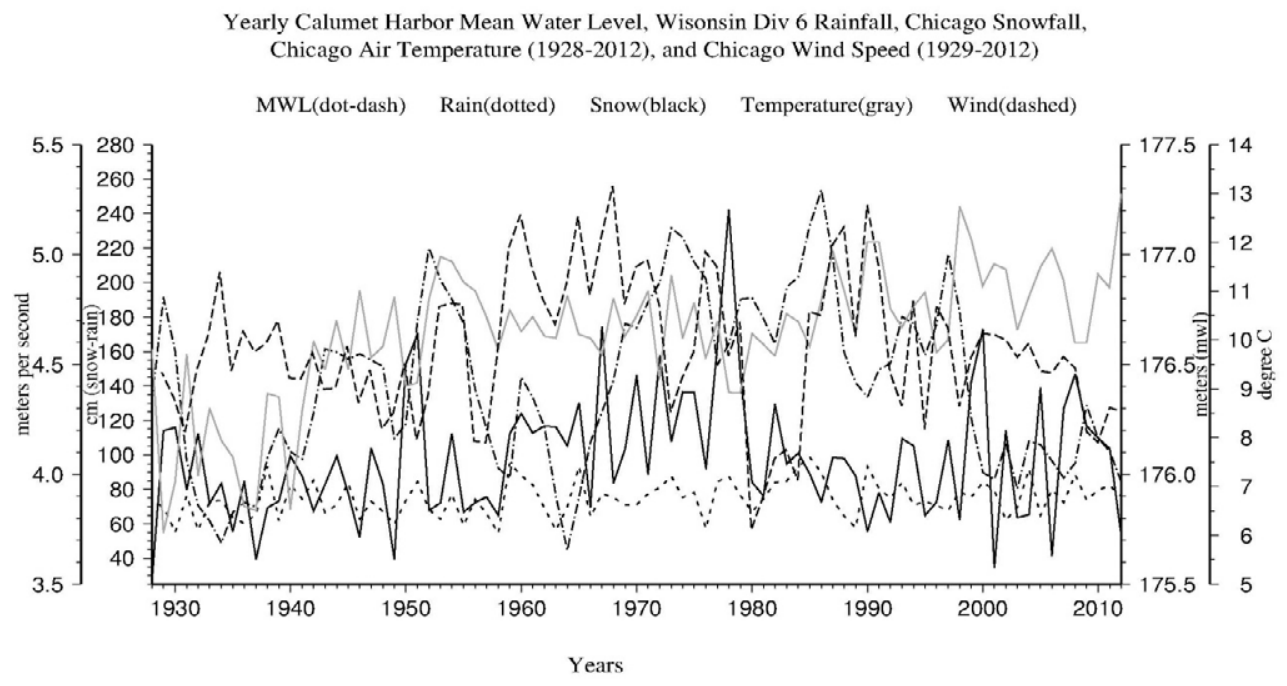

Figure 6: Annual averages of water level, rainfall, air temperature and snow accumulation of the collective time series from January 01,1928 to December 30,2012 in the Chicago, Lake Michigan area.

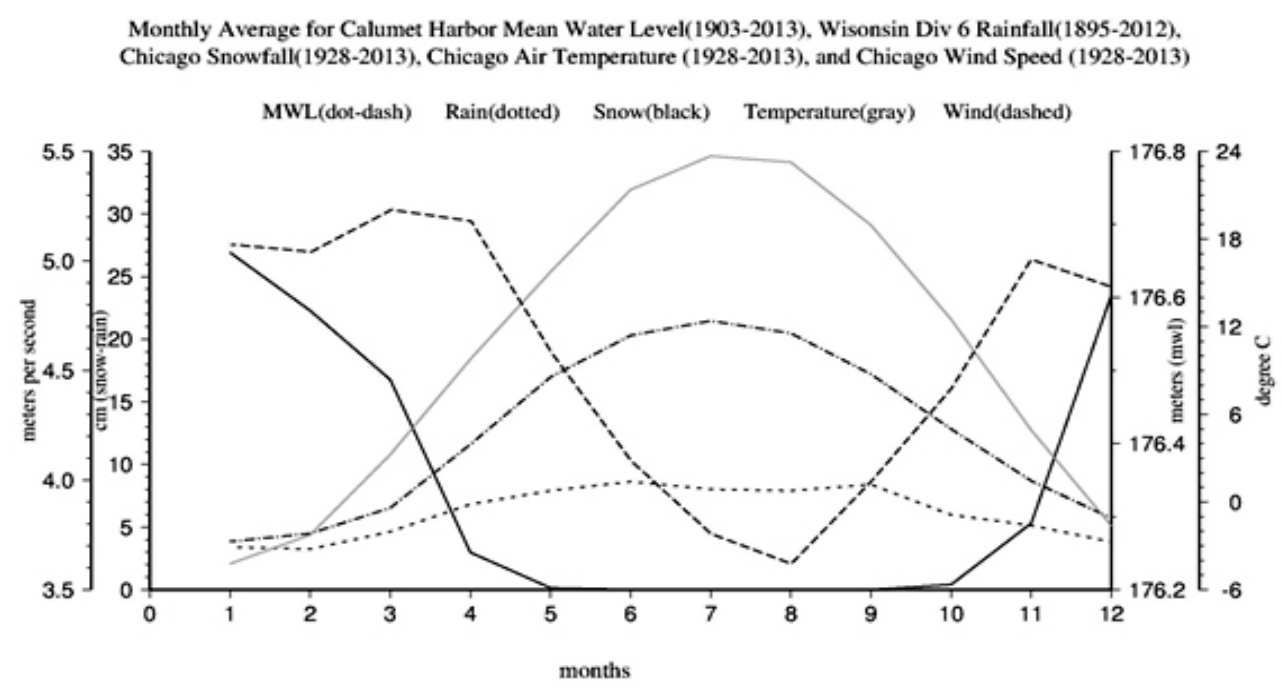

Figure 7: Average annual values, by month, of water level, precipitation, winds, snow accumulation and air temperature for the Lake Michigan domain. Snow accumulation levels are inches of snow and not converted to melted water levels. 
Figure 7 is included to provide perspective on individual record length monthly averages of the state variables. When treated in this manner, annual positive relationships and inverse relations between variables become clearer. On a monthly basis, water levels are at $176.3 \mathrm{~m}$ in January, rising to $176.4 \mathrm{~m}$ in April and to $176.5 \mathrm{~m}$ in June, to $176.6 \mathrm{~m}$ in July, back to $176.5 \mathrm{~m}$ in August and then $176.3 \mathrm{~m}$ in December. Annually rainfall ranges from a low of $2.54 \mathrm{~cm}$ in each of January and February rising to $8.9 \mathrm{~cm} /$ month from June through September and then falling again to $2.54 \mathrm{~cm}$ in December. Winds are at $5.1 \mathrm{~m} / \mathrm{s}$ in January to $5.3 \mathrm{~m} / \mathrm{s}$ in March and April then decline to $3.7 \mathrm{~m} / \mathrm{sec}$ in August and rise back up above $5 \mathrm{~m} / \mathrm{sec}$ by November. Snow accumulation is at $7.6 \mathrm{~cm}$ in January and decreases to $2.54 \mathrm{~cm}$ in April and to $0 \mathrm{~cm}$ by May then begins anew in late September and early October to $5.1 \mathrm{~cm}$ by November and $25.4 \mathrm{~cm}$ by December. Air temperature ranges from $-4^{\circ} \mathrm{C}$ in January to $-2^{\circ} \mathrm{C}$ in February rising to $21^{\circ} \mathrm{C}$ in June, $24^{\circ} \mathrm{C}$ in July, $23^{\circ} \mathrm{C}$ in August and dropping to $-2^{\circ} \mathrm{C}$ by December. So, the annual cycle of water level is positively correlated with rainfall (though the latter does not vary too much on a monthly basis) and air temperature and is inversely proportional with the wind field speeds and snowfall accumulations. However, when the represents a phase lag between water level and snowfall variables, as when the snow melts in the spring, water level rises from the additional water. We did not compute any phase lag cross-correlations between state variables.

Relying solely on traditional visualizations and data treatment, there appears to be a host of causal relationships between the annual cycle of water level and a myriad of environmental factors. The potential nature of these relationships, however, requires more in depth analyses, and perhaps deterministic numerical modeling from climate to local scales, to attempt elucidating which factors might be most strongly influencing water levels and on what time scales. To better evaluate the internal functions that may be buried within the data sets the HHT and subsequently EEMD will be applied to the data time series records. From (Figures 8a-d), we find that several temporal modes of variability are common or rather "intrinsic" to all of the data sets. They are monthly (except for the Chicago annual snow accumulation data set, as nominally half of the months are zeros).

The EEMD of the monthly water level time series for Calumet Harbor, Chicago (Figure 8a) IMFs display: C1, an intra-seasonal signal; $\mathrm{C} 2$, annual, with amplitude $\pm 20 \mathrm{~cm}$; C3, inter-annual, amplitude \pm 12 $\mathrm{cm}$; C4, 3-5 years, amplitude $\pm 20 \mathrm{~cm}$; C5,7-9 years, amplitude $\pm 30 \mathrm{~cm}$; C6, 15 - 17 years, amplitude $\pm 12 \mathrm{~cm}$; C7, 36-38 years, with amplitude \pm $20 \mathrm{~cm} ; \mathrm{C} 8, \pm 10 \mathrm{~cm}$ with a $\sim 110$ year cycle; and Mode C9, the trend, which is downward. Here we see, for example, that if one were to have monitored water levels from 1965 to 1987 only, one would assume that water levels were at record highs and that condition would likely remain. The reason for that was that Modes C4, C5, C6 and C7 all had positive first derivatives; contemporaneously. However, that is clearly a distorted picture, as the shorter term fluctuations are misrepresentative of the overall trend. The message is: the longer the record, the more the information.

In the 118 year continuous rainfall time series from Division 6 in Wisconsin (Figure 8b), the EEMD decomposition shows that IMF Mode: $\mathrm{C} 1$ is an intra-seasonal signal, $\mathrm{C} 2$ is seasonal with amplitude of order $\pm 7.5 \mathrm{~cm}$; $\mathrm{C} 3$ is annual with amplitude $\pm 4 \mathrm{~cm}$; 4 is inter-annual to 2 years at $\pm 1.8 \mathrm{~cm}$; $\mathrm{C} 5$ is a $3-5$ year signal, amplitude $\pm 1 \mathrm{~cm}$; 66 is $7-9$ years, $\pm 0.75 \mathrm{~cm}$; C7 is $16-18$ years, $\pm 0.5 \mathrm{~cm}$; C 8 is $37-39$ years, \pm $0.4 \mathrm{~cm}$; and C9 is a lengthy 114 years with amplitude $\pm 0.25 \mathrm{~cm}$.

The EEMD monthly time series of the 85 -year, continuous air temperatures from Chicago (Figure 8c) is very revealing relative to the Calumet Harbor water level time series Figure 8a. Mode C1 is intraseasonal with amplitudes $\pm 7^{\circ} \mathrm{C}, \mathrm{C} 2$ is annual and $\pm 15^{\circ} \mathrm{C}, \mathrm{C} 3$ is biennial and $\pm 2^{\circ} \mathrm{C}, \mathrm{C} 4$ is $3-5$ years and $\pm 1.5^{\circ} \mathrm{C}, \mathrm{C} 5$ is $7-9$ years and $\pm 0.8^{\circ} \mathrm{C}, \mathrm{C} 6$ is $15-17$ years and $\pm 0.7^{\circ} \mathrm{C}, \mathrm{C} 7$ is $\sim 40$ years and $\pm 0.6^{\circ} \mathrm{C}$, and $\mathrm{C} 8$ is $\sim 75$ years and $\pm 0.2^{\circ} \mathrm{C}$. In terms of the water level in-kind Figure $8 \mathrm{a}$, the air temperatures are totally consistent in periods and amplitude ranges; from an inverse perspective. The IMFs of vertical snow accumulation (Figure 8d) show that: $\mathrm{C} 1$ is annual, and of amplitude $\pm 50 \mathrm{~cm}$; 2 is 8 years, and amplitude $\pm 25 \mathrm{~cm}$; and $\mathrm{C} 3$ is $\sim 17$ years, and amplitude of $\pm 25 \mathrm{~cm}$; C4 is nominally about 25 years with peak amplitudes of \pm 25 $\mathrm{cm}$; and C5 is $\sim 50$ years with amplitudes of +15 and $-10 \mathrm{~cm}$.

The most recent threat from low lake levels came over the period January-March 2013 Figure 8a when the water levels reached nearrecord lows of $175.5 \mathrm{~m}$, and greatly impacted the amount of goods that could be transported on cargo vessels, which threatened the stability of the energy sector [14]. Two additional exceptionally low water level episodes occurred in 1963-1966 and 1996-2001. During the 1996-2001 5-6 year episodes, reports from cargo transports indicated a decrease in carrying capacity by $5-8 \%$ forcing the shipping companies to lighten their loads, which lead to a reported year to year decline of $6.7 \%$ in dry bulk goods.

In Figure 9 we present the record length trends of mean water level, rain, vertical snow, air temperature and wind speed in the Chicago domain, over the period 1928-2012; keeping the time series in sync. Over the 85 year period addressed in Figure 9: 1) the dynamic normal of precipitation has risen from $71 \mathrm{~cm} / \mathrm{yr}$. in January 1928 to $78.8 \mathrm{~cm} /$

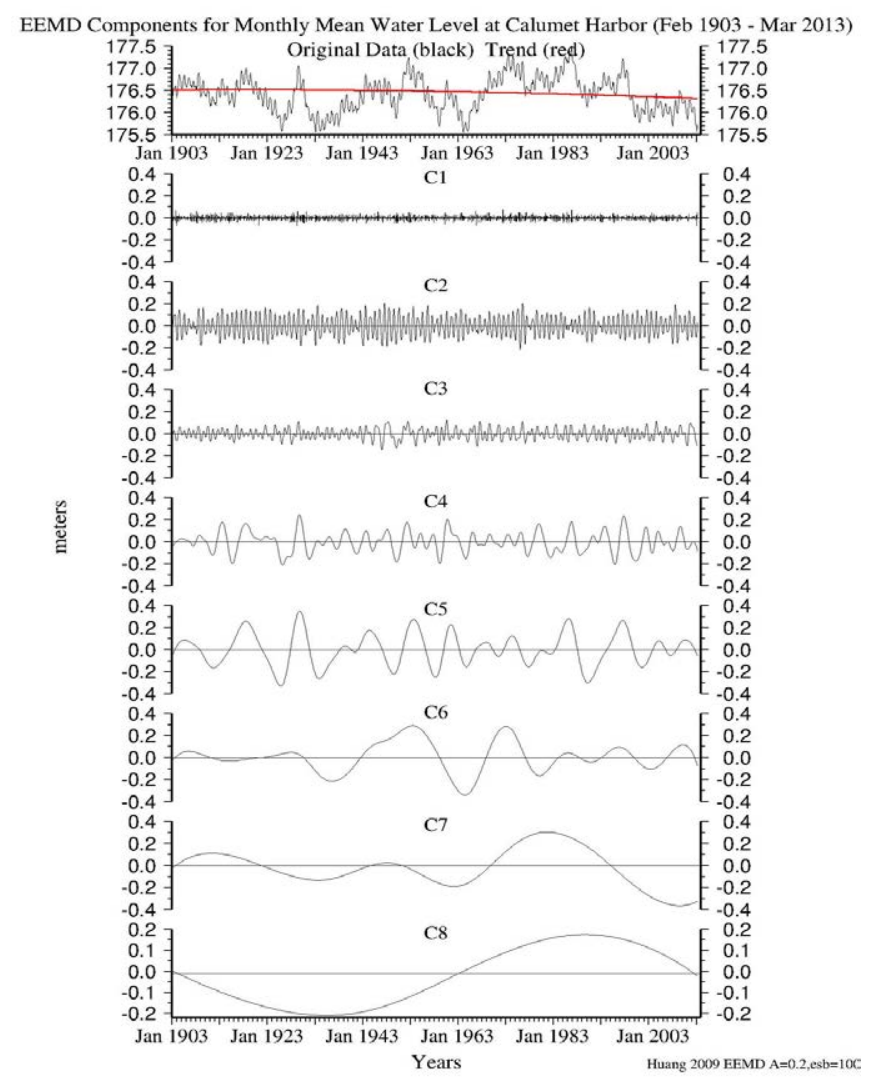

Figure 8A: Intrinsic mode function decompositions of: a) upper left panel, water level in Calumet Harbor, Lake Michigan. 
Citation: Pietrafesa LJ, Shaowu Bao, Huang NE, Gayes PT, Yan T, et al. (2016) Great Lakes Water Levels: Decomposing Time Series for Attribution. J Climatol Weather Forecasting 4: 153. doi:10.4172/2332-2594.1000153

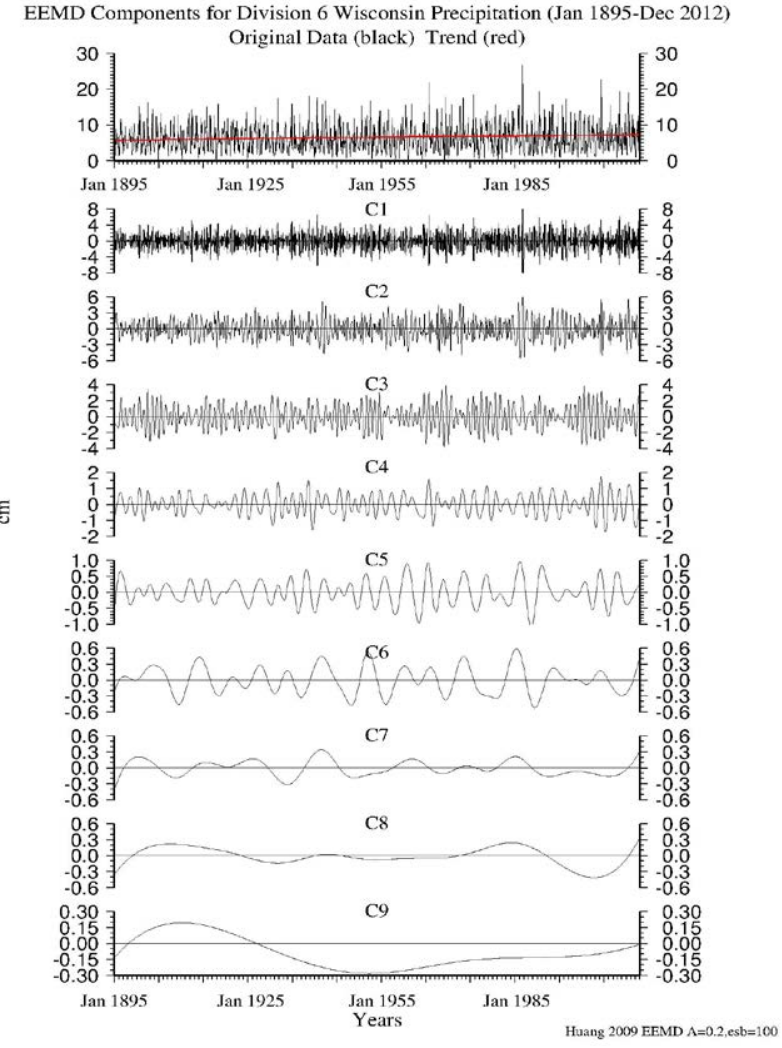

Figure 8B: Upper right panel, rainfall in Zone 6 adjacent to Lake Michigan.

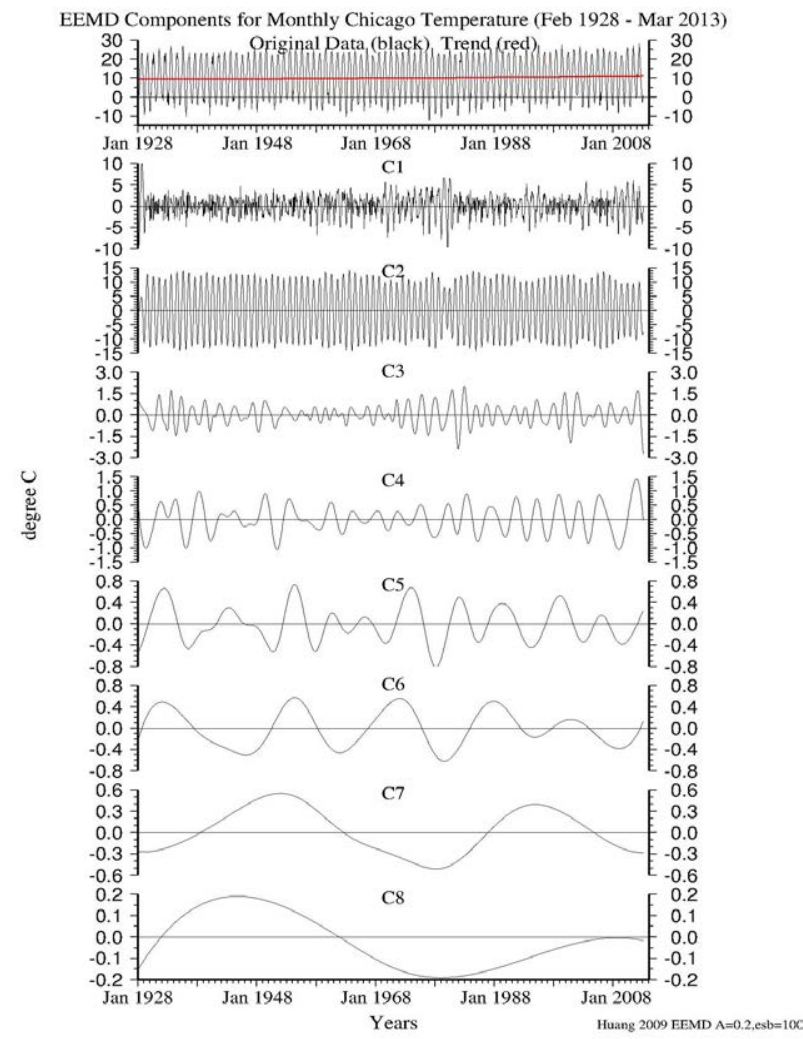

Figure 8C: Lower left panel, vertical snow accumulation in Chicago.

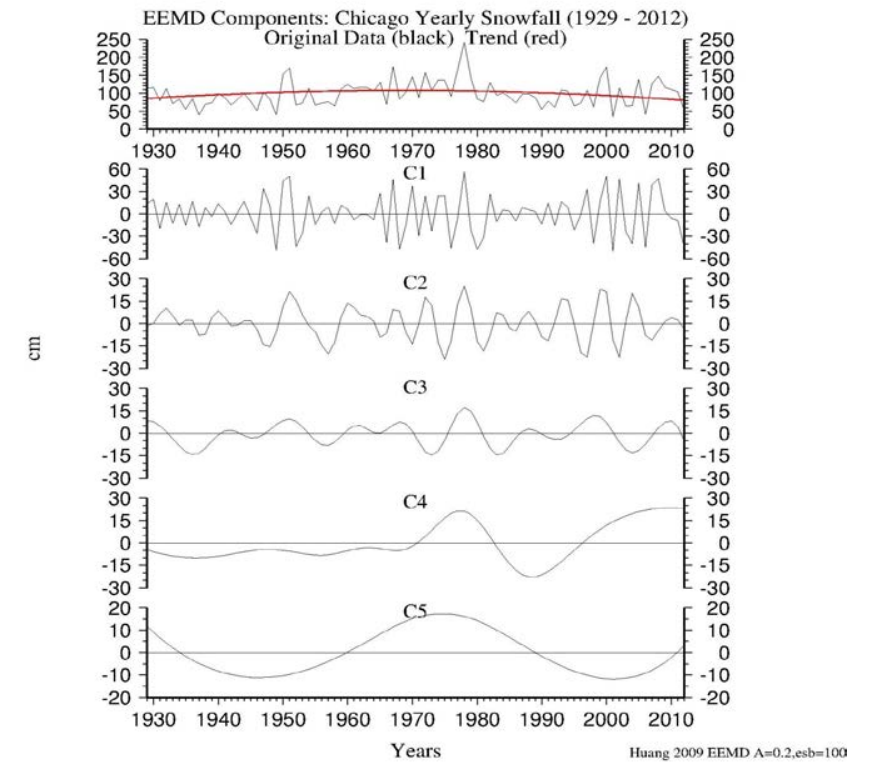

Figure 8D: Lower right panel, air temperatures in Chicago. The red lines in the upper panels depict the trends in the respective time series.

yr. in January 2013 in a quasi-linear upward rise of $7.8 \mathrm{~cm} ; 2$ ) the snow accumulation dynamic normal accumulations were at $85.1 \mathrm{~cm}$ in 1928 , rose quasi-parabolic ally to $114.3 \mathrm{~cm}$ around the mid-1980s and then decreased quasi-parabolic ally to $80.0 \mathrm{~cm}$ though 2012; an overall drop of $5.1 \mathrm{~cm}$ or in conversion of $25.4 \mathrm{~cm}$ in of snow per $2.54 \mathrm{~cm}$ of rain then the drop has been $\sim 0.51 \mathrm{~cm}$ of water; 3 ) the air temperature dynamic normal varied from $9.5^{\circ} \mathrm{C}\left(49.1^{\circ} \mathrm{F}\right)$ in 1928 to $9.48^{\circ} \mathrm{C}$ in $1933,10.0^{\circ} \mathrm{C}$ in 1980 and then rose to $11.1^{\circ} \mathrm{C}\left(52^{\circ} \mathrm{F}\right)$ through 2012 ; constituting an overall rise of $1.6^{\circ} \mathrm{C}\left(2.9^{\circ} \mathrm{F}\right)$; and 5) the water level dynamic normal decreased quasi-linearly from $176.50 \mathrm{~m}$ in 1928 to $176.32 \mathrm{~m}$ in 2012, an overall drop of $18 \mathrm{~cm}$ (7.08 in); and e) wind speeds rose from 4.35 $\mathrm{m} / \mathrm{s}$ in 1928 to $4.7 \mathrm{~m} / \mathrm{s}$ in the $1960 \mathrm{~s}$ to $4.5 \mathrm{~m} / \mathrm{s}$ in early 2013 so depict an overall increase of $1.5 \mathrm{~m} / \mathrm{s}$. In summary, water levels have gone down, snow accumulation rose then fell but overall have dropped, wind speeds rose then fell, with an overall rise, rainfall has risen and air temperature has risen.

In an attempt to address any potential heat island effects related to air temperatures in Chicago, a major metropolitan city with many buildings, etc., the temperature record of nearby Aurora, IL is used by way of comparison to that of Chicago's. The time series (not shown) extended from 1895 to 2012 , and began at $8.97^{\circ} \mathrm{C}$ in 1895 , dropped to $8.78^{\circ} \mathrm{C}$ in 1933 and then rose to the present $9.67^{\circ} \mathrm{C}$, and displayed a $-0.01^{\circ} \mathrm{C} / \mathrm{yr}$. rate in 1895 , about $-0.001^{\circ} \mathrm{C} / \mathrm{yr}$. in 1928 and has risen to the present day rate of $+0.025^{\circ} \mathrm{C} / \mathrm{yr}$. Chicago's air temperature time series began in 1928 at $9.49^{\circ} \mathrm{C}$ at a rate of $\sim-0.001^{\circ} \mathrm{C} / \mathrm{yr}$., bottomed out around 1930 at $9.48^{\circ} \mathrm{C}$ and was at $11.10^{\circ} \mathrm{C}$ in 2012 , with its' annual rate of warming having risen to $+0.042^{\circ} \mathrm{C} / \mathrm{yr}$. Aurora and Chicago both have relatively high rates and comparable rates of warming. So the overall rate of warming of the atmosphere as suggested by the Chicago air temperature record is entirely consistent with a nearby air temperature record in an arguably non-urban island environment.

In Figure 10, we show the monthly averaged water levels in Calumet Harbor, Lake Michigan and the slope of the overall change, or documented rate of rise and/or fall. Over the first two decades of the 
Citation: Pietrafesa LJ, Shaowu Bao, Huang NE, Gayes PT, Yan T, et al. (2016) Great Lakes Water Levels: Decomposing Time Series for Attribution. J Climatol Weather Forecasting 4: 153. doi:10.4172/2332-2594.1000153

EEMD Trends for Calumet Harbor Mean Water Level, Wisonsin Div 6 Rainfall, Chicago Snowfall, Chicago Air Temperature, and Chicago Wind Speed (1928-2012)

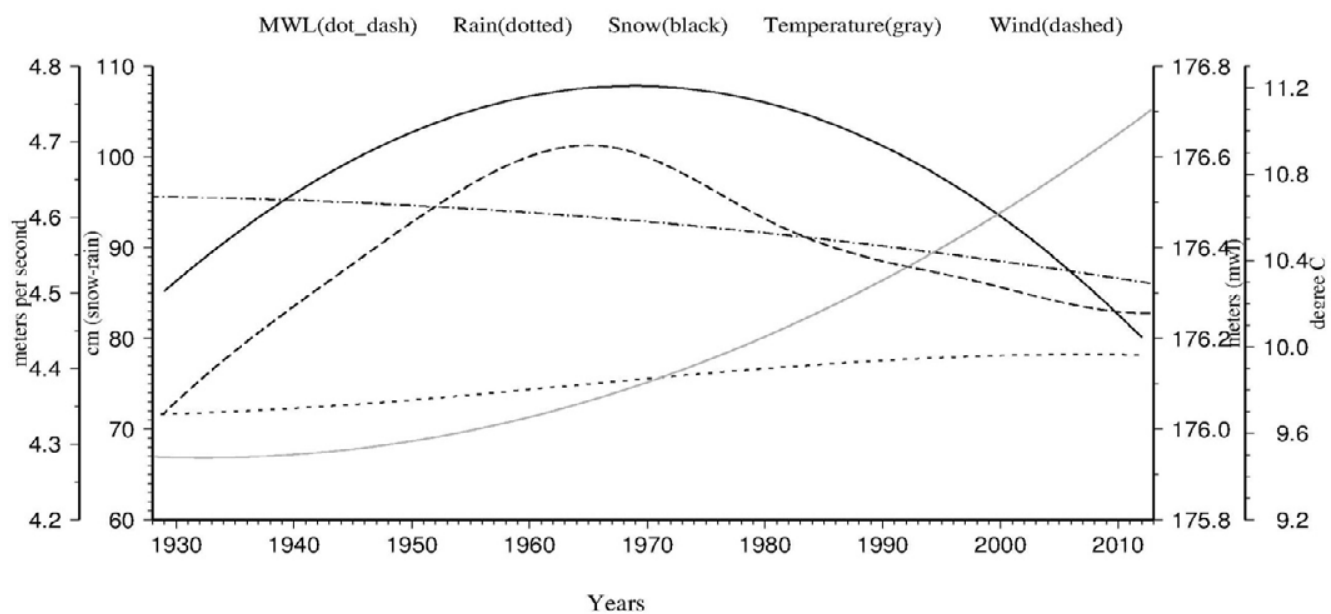

Figure 9: Time series record length Trends of water level, rain, snow accumulation, winds and air temperatures of and adjacent to Lake Michigan. All of the time series were cut to 1928 so that they are of the same length in time; though several are longer.

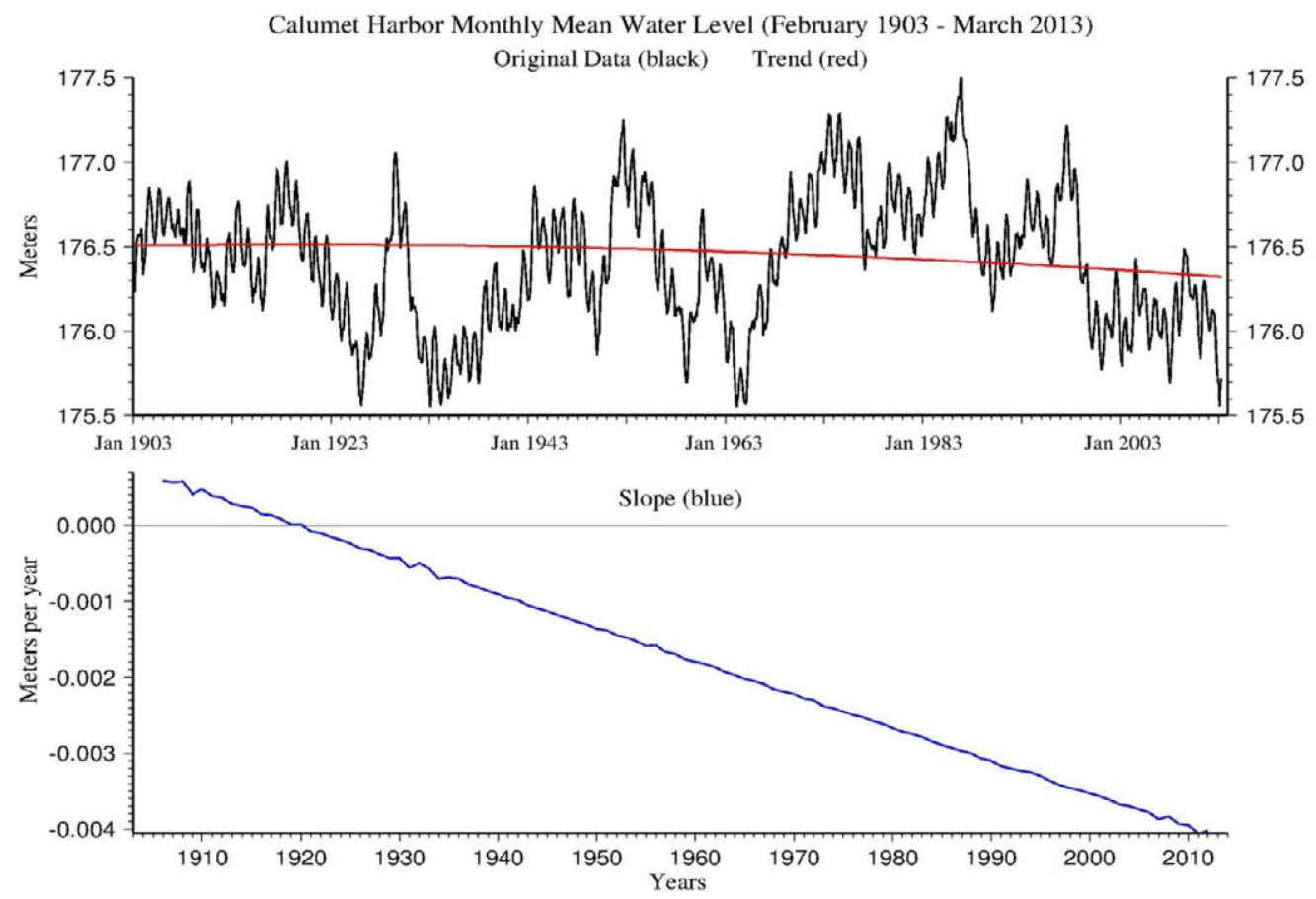

Figure 10: (Upper panel) Calumet Harbor monthly mean water level time series and trend (red line) from 1903 to 2013 and (Lower panel) time rate of change of the trend (blue line).

$20^{\text {th }}$ Century the rate of change of water level per annum was positive but decreasing and by 1920, the rate became negative. By 2012 this rate was $\sim-0.45 \mathrm{~cm} / \mathrm{yr}$. This is sync with the aforementioned rates of rise of air temperatures of $+0.025^{\circ} \mathrm{C} / \mathrm{yr}$ in Aurora and $+0.042^{\circ} \mathrm{C} / \mathrm{yr}$. in Chicago. So the conclusion that one could reach is that evaporation due to rising air temperatures, and presumably surface lake water temperature, could be responsible for some of the observed drop in water level. We will test this assumption.

The simplest scenario for the calculation of evaporation in keeping with Fairall et al. [12] would be to assume $\mathrm{T}_{\text {air }}=\mathrm{T}_{\text {water }}$, and humidity would hold constant at $70 \%$. The formula is: $E=\rho_{a} C S\left(q_{s}-q\right)$, where $\mathrm{E}$ is the evaporation rate, $\rho_{a}$ is the air density, $C_{e}$ is the transfer coefficient for latent heat, $S$ is the average value of the wind relative to the water surface at a reference height, $q_{s}$ is the saturation mixing ratio for pure water at the water temperature, and $q$ is the air mixing ratio $q=R H$ $q_{s}(T)$, where $R H$ is the relative humidity and $T$ is the air temperature. This simple idealized calculation suggests that the resulting evaporation could have caused $1.71 \mathrm{~m}$ of a water level drop from 1895 to 2013. If we 
then linearly increase the temperature by $1^{\circ} \mathrm{C}$ from 1895 to 2013 , and re-calculate the evaporation, it would have caused a $1.78 \mathrm{~m}$ water level drop. So the increase in T would have caused an overall $7 \mathrm{~cm}$ water level change. To evaluate this further, we also conducted a more complete calculation of evaporation vs. air temperature as prescribed in Fairall et al. [12] As lake surface water temperatures are needed for the more complete calculation, we utilized a data set of temperatures, which were obtained from actual Lake Michigan surface water temperature time series NCEP/NCAR Reanalysis data archives, and reached the same conclusions.

Comparisons of the EEMDs of the monthly time series and of the surface water temperatures in Lake Michigan and the air temperatures in the city of Aurora (neither is shown), reveal 7 intrinsic modes of variability. These modes include seasonal, annual, biennial, 3-5 year, 6-8 year, 15-16 year and 32-35 year modulated cycles with comparable amplitudes on a mode by mode basis. The trends and rates of change of those trends of the temperatures over the same time series record lengths, from January 1949 through September 2013, presented in Figure 11, show that the averaged water temperatures ranged from $8.22^{\circ} \mathrm{C}$ at the onset of the water temperature record in 1949 to $7.70^{\circ} \mathrm{C}$ in 1979 to $8.97^{\circ} \mathrm{C}$ by record end with a bottoming to $7.70^{\circ} \mathrm{C}$ in 1979 . Meanwhile, the air temperature time series began at $8.81^{\circ} \mathrm{C}$ in 1949 , bottomed at $8.54^{\circ} \mathrm{C}$ in 1965 and peaked at $10.42^{\circ} \mathrm{C}$ at record end. This constitutes 64.75 year record length differentials of $0.75^{\circ} \mathrm{C}$ in the water temperature and $1.61^{\circ} \mathrm{C}$ in air temperature. Data obtained from the NCEP/NCAR reanalysis yields the end points of the time series to be $8.22^{\circ} \mathrm{C}$ in January 1949 and $8.97^{\circ} \mathrm{C}$ in September 2013. This translates to a rate of increase of $+0.012^{\circ} \mathrm{C} /$ year. Using this value and then calculating the contribution of the process of evaporation's to lake level change, it is found that over 100 years the difference in Great
Lake water level could be $40.6 \mathrm{~cm}$ (16 in); in keeping with the above estimates.

In Figure 12 the overlapping plots of the Calumet water level IMF 8 plus the overall trend are summed and plotted against the Aurora air temperature IMF 8 summed with its overall trend. The results indicate a 110 year, inverse modulation in the two time series; very suggestive of relationships between lake water levels and air temperatures over long period climate factors. We use this agreement as the basis for examining data in (Figures 13 and 14).

In Figure 13, we see the long term trends summed with IMF modes 8 of the Global Surface (land and ocean) Temperature Anomaly (GSTA) time series versus those of Calumet Harbor water level and Aurora air temperature. The GSTA and AAT are proportional while the GSTA and CWL are inversely proportional. In Figure 14, we see the long term trends summed with IMF modes 8 of the Atlantic Multi-decadal Oscillation (the AMO Index) time series versus those of Calumet Harbor water level and Aurora air temperature. The AMO index is calculated at the NOAA Earth Systems Research Laboratory Physical Sciences Division (PSD) by using the Kaplan SST data set $(5 \times 5)$, determining the area-weighted average over the North Atlantic over $0-70 \mathrm{~N}$. We see that the AMO and AAT are proportional and inphase while the AMO and CWL are inversely proportional.

\section{Discussion}

This study was conducted to scientifically investigate the perceived drops in water levels that have been reported upon by multiple public news media sources. The results of this study of water level variability and overall trends in the Great Lakes of the United States and Canada and were initiated with the exploration of basic correlations between some of the most basic potential, causative, drivers of water levels in

Aurora, IL and Lake Michigan Monthly Temperature EEMD Trends (January 1949 - September 2013)

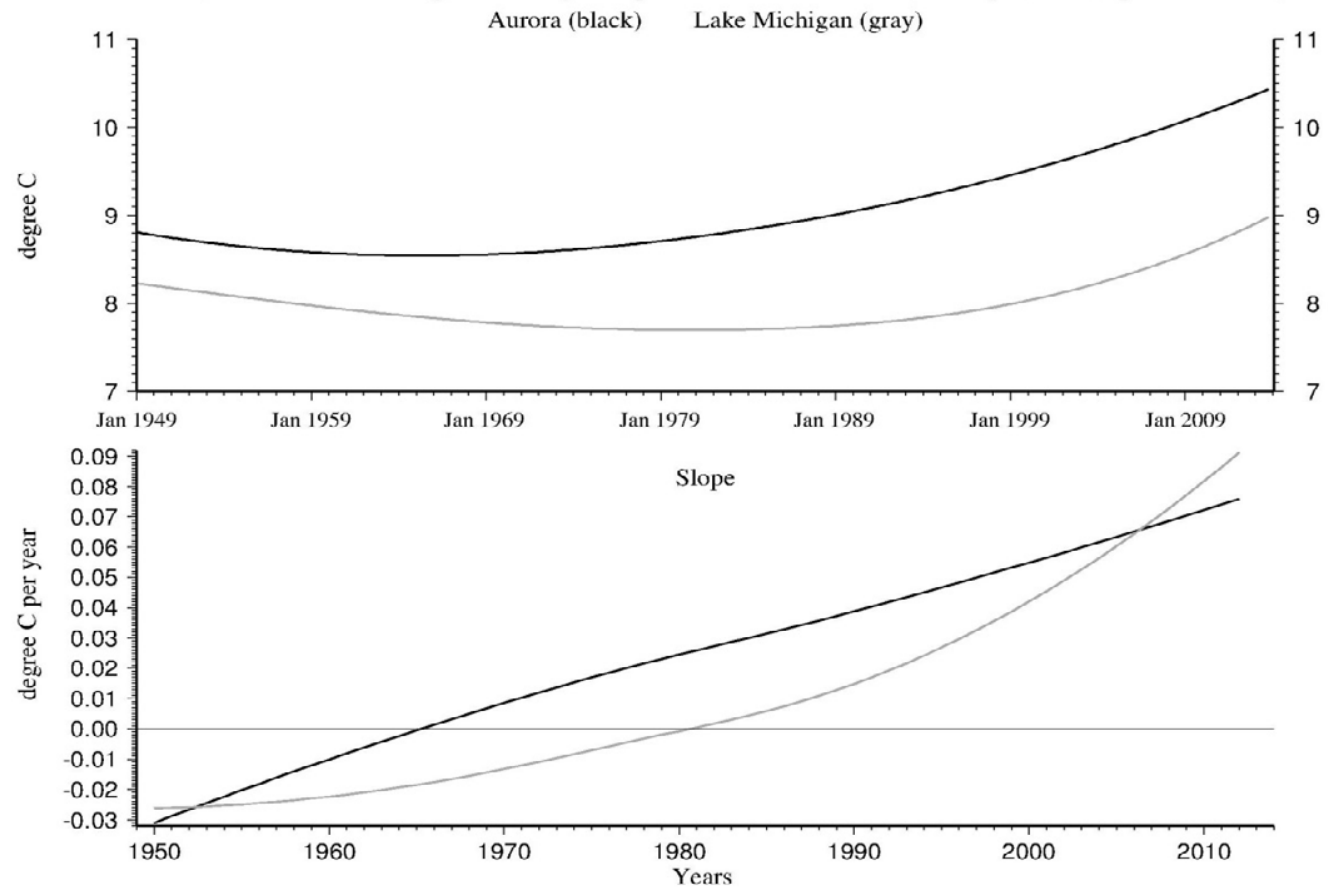

Figure 11: (Upper panel) Trends of Aurora air temperature (black line) and Lake Michigan surface water temperature (gray line) time series from January 1949-September 2103. (Lower panel) Time rates of change of the Aurora air temperature trend (black line) and the Lake Michigan surface water temperature trend (gray line). 
Citation: Pietrafesa LJ, Shaowu Bao, Huang NE, Gayes PT, Yan T, et al. (2016) Great Lakes Water Levels: Decomposing Time Series for Attribution. J Climatol Weather Forecasting 4: 153. doi:10.4172/2332-2594.1000153

Monthly Aurora Temperature and Calumet Harbor Mean Water Level (February 1903 - March 2013) EEMD mode $8+$ trend

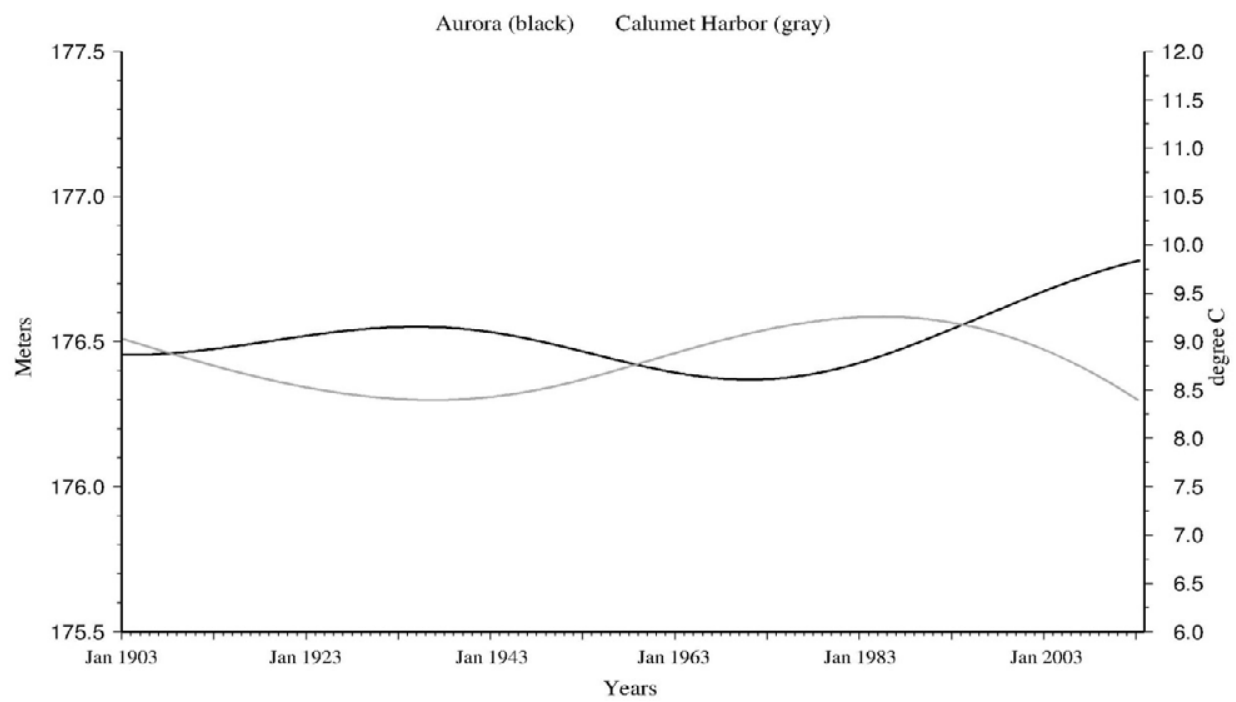

Figure 12: The record length trends plus the respective 110 year IMF modes 8 of Calumet Harbor water level and Aurora air temperature.

EEMD M8+Trend for Calumet Harbor Water Level,Aurora Temperature, and Global Land-Ocean Temperature Anomaly (1903-2013)

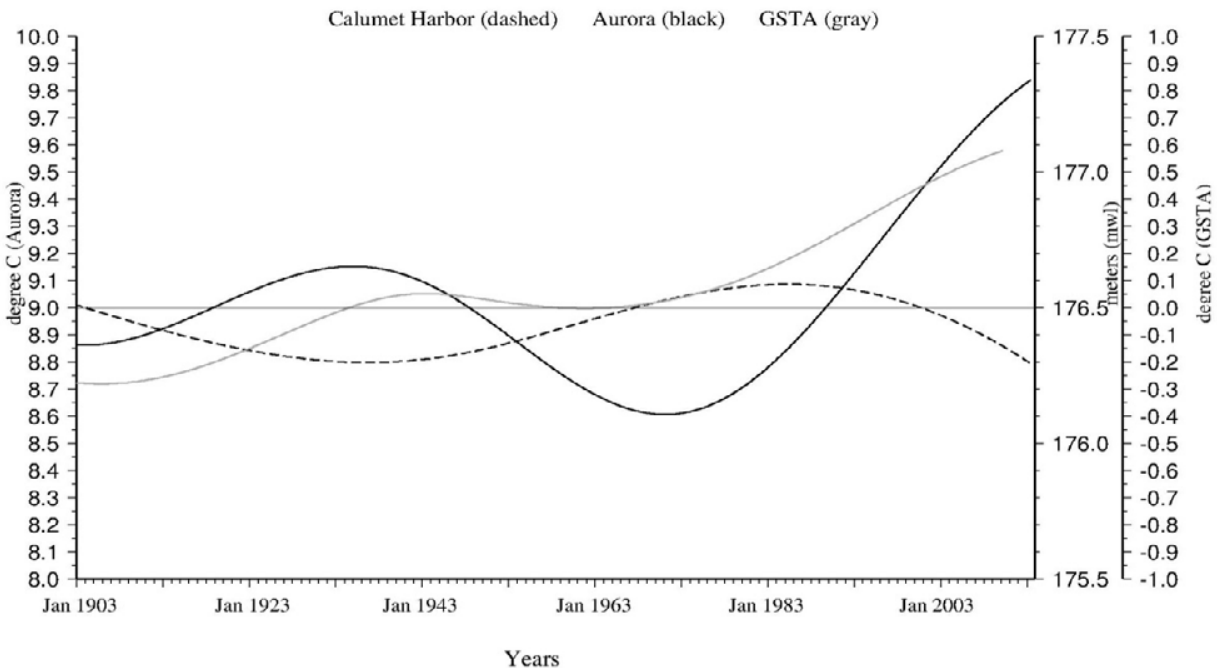

Figure 13: Respective record length trends summed with respective IMF Modes 8 of the GSTA (gray), Calumet Harbor Water Level (dashed) and Aurora Air Temperature (black) from 1903-2103.

the Great Lakes. Visual correlations between various state variable environmental time series did not reveal straight forward conclusions as the time series were clearly strongly non-stationary and non-linear. Consequently a mathematical methodology was utilized to decompose the various time series into their internal modes of variability and overall record length time series trends. Also, in the study, given that there are five Great Lakes with a plethora of environmental time series for each, we focused on Lake Michigan as being representative of the entire suite of lakes.

The inter-comparisons demonstrated strong agreement between water levels from individual great lake to individual great lake and also to atmospheric precipitation over time, but the steady decline in water levels in the Great Lakes is not linked to any corresponding decline in precipitation values over the record lengths of the respective time series. While rainfall has varied significantly annually and interannually, overall amounts have remained stable; while not so with water levels. These results support similar findings by Angel and Kunkel [7] who found both wetter and drier conditions were possible based on the GCM simulations, but those variations were coupled so closely to water level that swings from -3 to +1.5 m were produced, which doesn't match ranges that we found in the water level time series.

The annually averaged data sets revealed the internal scale of 


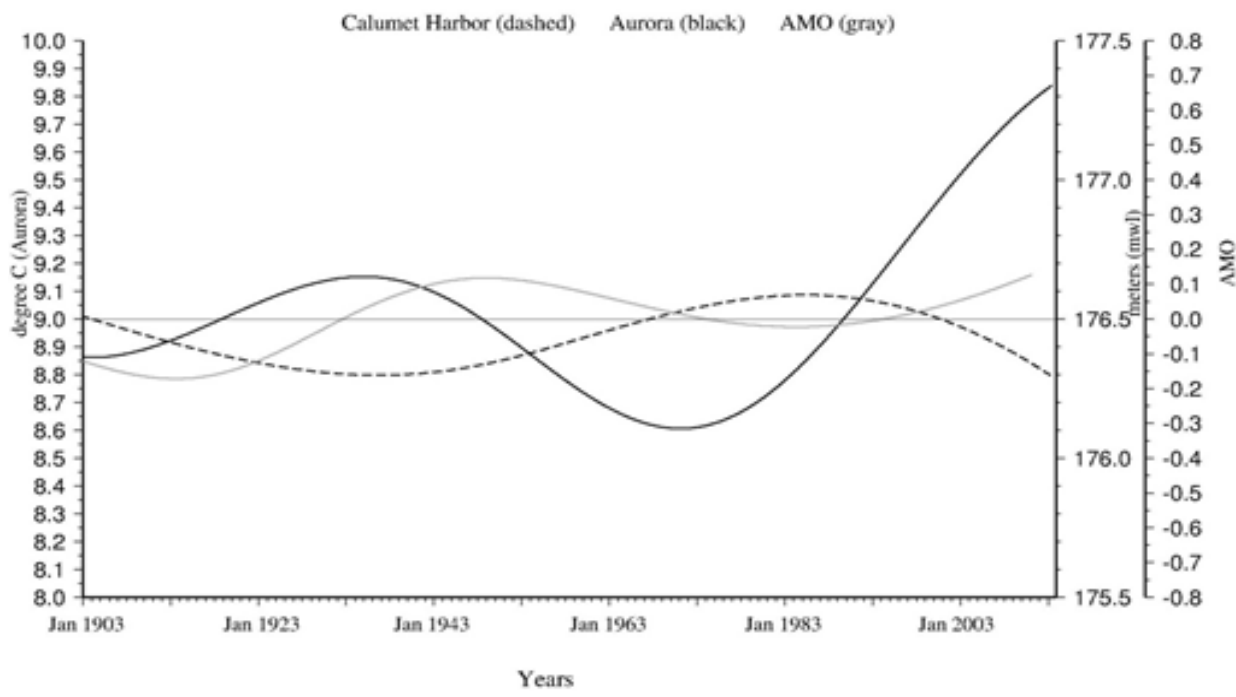

Figure 14: Respective record length trends summed with respective IMF Modes 8 of the AMO (gray), CWL (dashed) and AAT (black) from $1903-2013$.

variability buried in each of the data sets, a gradual rise in temperature, gradual decline in water level and highly variable though fairly consistent rainfall increasing, along with decreasing snow accumulation. Even in the longer data sets there appeared to be no definitive trends on which to base solid conclusions due to the large variability over time amongst the various time series. When viewed along with the monthly averages, we showed the importance of decomposing the internal signals buried within the data along with very strong seasonal signals wherein water level was directly proportional to temperature and rainfall and inversely proportional to snow and wind intensity. On the surface, some of this would seem counter-intuitive, but snow melt would only provide water that may affect lake level during melt. During the winter months when winds are elevated, the lakes may be capped with ice, decreasing the evaporative loss to enhanced wind fields. So the causal relationships between the annual cycle of water level, rainfall, snowfall, wind and temperature appear to coincide with what you would expect on a monthly basis over all years of available data. However, these findings don't allow for a clear understanding of the full range of time periods over which each of these factors may operate and impact water levels in Lake Michigan (and by proxy, provide a likely base for dynamics in the rest of the Great Lakes' system).

Among the environmental factors, there were surprisingly similar modes of variability in all factors except for snowfall, due to the number of months for which the value was zero making time periods shorter than seasonal impossible. Several of the signals are on timescales that can be casually observed by most people, that of seasonal, annual and even inter-annual. At those scales, the public are capable of making some anecdotal assessments that compare changes in environmental factors. However, the modes that were apparent on longer time periods such as 3-5 years, 6-8 years, 10-12 years and longer demonstrate just how dynamic these environmental factors are and the difficulty managers may face in addressing water levels issue as timing among the IMFs may align. Even longer modes of variability were present in each of the time series, up to 42 years for water level, potentially 105 years for rainfall, 45 years for temperature and up to 50 years for snowfall. Attempting to account for the confluence of these signals and how they may impact water level over those timescales is exceptionally difficult and underscores how little may be known regarding the manner in which these factors can align to drastically influence the water level in any given time frame. Particularly, the corresponding frequencies of variability buried within the temperature and water level series seem coincident though the phase doesn't always seem to align. A similar agreement was seen when comparing temperature to wind patterns in that modes of variability were largely coincident on time scales under 10 years indicating potential relationships between temperature and wind.

Our results show what appears to be a significant rising trend in air temperature in the Chicago environ, over the time series which extends from 1928-2013. However the gravest mode in the wind speed fields show a slight rise from 1928 to the 1960s and then a slight drop. This is an important distinction in determining if one of these two factors may have a larger impact on the measured water levels. We note that static normal, digital single number averages, such as those employed by NOAA for 30 periods initiated with years ending in zero would be fairly consistent for the precipitation trend while those of temperature, snow accumulation, winds and water level would be very different for the 30 year period of $1930-1960$ versus those, say of $1960-1990$. We repeat that dynamic normal do not produce a single digit value but rather change with time as they do in nature. We note that the time period of overlapping data sets covers 85 years. As has been pointed out above, the cycles that emerge from the EEMD decompositions are all in sync. For example, one can see in the decompositions of the time series that precipitation time series has an oscillation nominally from 1970 to 2010 and that very same oscillation is present in the water level time series and likewise in the air temperature time series.

The data trends indicate that wind speeds, rainfall and temperature have all increased non-linearly over the record length time series while water level and snowfall have declined. One would expect the increase in rainfall to produce an increase in the water level so it seems unlikely that rainfall (or lack thereof, rather) is a driving force behind recent, record lows. Both increased temperature and wind speeds would be expected to enhance evaporation and decrease water levels, 
but despite overall increases in wind speed, the speeds only increased through 1965, but have since declined. An additional impact that rising temperature would be a steric increase in water level (particularly given increases in surface water temperature), but that this rise should be negligible given the minor temperature increase $\left(0.75^{\circ} \mathrm{C}\right)$ confined to the surface water temperature over the time series (discussed below). Based on expected physical relationships between these environmental factors it would stand to reason that the accelerating increase in air temperature is the strongest candidate for driving lower water levels. It's possible, however, that using the temperature record from Chicago could interject biasing from heat island effects; which is addressed by employing a nearby continuous air temperature time series.

The comparison using Aurora, IL air temperature records demonstrated similar slopes and total temperature increases between Aurora and Chicago. While the final temperature rise is slightly higher in Chicago that is that of Aurora, the record length for Aurora is actually longer by more than 30 years. There might, then, be a slight influence of heat island effect for the Chicago air temperature record, but the difference is modest. Using the Aurora air temperature record, a comparison between the air temperature record and surface water temperature record (for Lake Michigan) demonstrate coherence at shorter time scales (less than 5 years) while longer term signals diverge greatly. The overall trend of temperature change between the two is very similar, while the rate of temperature change is dynamic between the two with faster acceleration present in the surface water of Lake Michigan (the likely cause of the lack of coherence over longer time periods). Even with the Aurora record, it is clear that temperature increases in Lake Michigan surface water track well with air temperature increases, though the annual rate of increase demonstrates more of an accelerating increase for the Lake.

If the rising air temperatures and the increased evaporation in the Great Lakes area are responsible for the dropping water levels, then the present warming rates of Chicago, which clearly has been and remains an urban heat island, and Aurora, which is more likely the truer representative of the overall rise of air temperatures in the Great Lakes region, at $+0.025^{\circ} \mathrm{C} / \mathrm{yr}$., and a falling water level rate of $0.4 \mathrm{~cm} /$ yr. are each at extremes in their respective time series. This computes to a recent rate of $16 \mathrm{~cm}(6.3 \mathrm{in})$ of drop per $1^{\circ} \mathrm{C}$ of air temperature rise. If these rates were to continue, then in 10 years water levels will be 4 $\mathrm{cm}$ lower than at present in Lake Michigan and in 50 years the drop will be $40 \mathrm{~cm}$; likely not insignificant to boating and shipping interests around the periphery of Lake Michigan, our surrogate for the entirety of the Great Lakes. But, this is all speculation without the quantification of potential changes in evaporative loss that would be attributed to changes in air temperature.

A basic calculation based on Fairall et al. [12]. Uses air temperatures, water temperatures, relative humidity, lake surface atmospheric pressure and wind speed. In a hypothetical scenario, when the temperature (both air and water) increased $0.3^{\circ} \mathrm{C}$ over the 33 years (1981-2013), the concurrent water level drop was about 5.6 $\mathrm{cm}$. This translates into a 100 -year period such that, a $1^{\circ} \mathrm{C}$ increase in temperature probably will lead to about a $16.5 \mathrm{~cm}$ water level drop. Recall that water level dropped at Calumet by $18 \mathrm{~cm}$ from 1928 to 2012. So, from this rough calculation, we find that evaporation due to warming could have accounted for the entire measured drop in lake level.

Post glacial rebound (PGR) may also play a role, though trends are drastically different in Lake Michigan depending on the location. As the glaciers began to recede some 20,000 years ago the tectonic plates would have isostatically adjusted to the change in overlying mass; the vertical crustal motion of the entire Great Lakes region was examined Mainville and Craymer [15]. The results reaffirms prior studies [1619] in which various geoid models, in concert with Global Positioning Satellite (GPS) data and tide gage data from around the five lake basins are all in agreement. There has been a tilt, a "see-saw" effect across the entire Great Lakes region such that there has been a rise of land in the northern part of the region and a subsidence of land in the southern portion of the region. In the locale of Calumet Harbor where we utilized the 111-year water level data set, the net result of the PGR tilt has been a drop of $10.4 \mathrm{~cm} /$ century. So over the 111 year period the net effect has been that there has been an $11 \mathrm{~cm}$ rise in water level relative to the falling land. So the overall drop in water level between 1903 and 2012 may actually have been $23.75 \mathrm{~cm}$

Now consider the overall trend of water level and Aurora air temperature and their separate IMF modes 8 . Recall that the sum of the water level IMF Mode 8 and its' overall trend were presented and plotted against the Aurora air temperature Mode 8 summed with its overall trend; producing quite a remarkable inter-comparison. To a very high degree of confidence, water level and air temperatures are coupled, interactively so, given the process of evaporation, such that there is a seemingly 110-year modulation of the trends of both time series. These results along with the general coherency of common frequencies among the all the environmental factors (save snowfall) lead to the possibility that the Great Lakes climate signals are being modulated, as a whole, in concert with a non-regional process. When EEMD was applied and trend lines were plotted for Aurora air temperature, Calumet water level and the Global Land-Ocean Temperature Anomaly and the Atlantic Multi-decadal Oscillation, very similar modes of variability for the overall trend were discovered. While only a preliminary look at these possible relationships, these synergies in trends seem to indicate a potential for Great Lakes regional responses to forces acting on similar time scales to global scale climate oscillators.

\section{Conclusion}

Water levels have been falling in the Great Lakes region, reaching record lows in 2013. Forty year time series of monthly water levels and precipitation demonstrated high visual correlations between water levels and rainfall across the five Great Lakes. However, annual averages of water levels, rainfall, snow accumulations, and air temperatures are not highly, visually correlated; thus creating a source of confusion in interpreting the various time series and establishing correlations that may elucidate the combination of driving forces that have led to the record low water levels. This forced use of records that contained longer time series of all state variables for Lake Michigan with temporal coverage between 85 and 119 years in length. The application of EEMD modal decomposition uncovered consistent internal, intrinsic modes of variability in all state parameters including: rainfall, snow accumulation, water level, and air temperature. Based on results of the EEMD, environmental state factors were found to be variable over similar seasonal, to annual, to inter-annual to decadal to multi-decadal modes.

Superimposed on all of the climatological variability is Post Glacial Rebound (PGR). The current isostatic adjustments in the region indicate that variation between the north and south would lead to falling water levels in the northern portion of the Lake Michigan basin, but not in the Southern (which we used for our test case) and therefore cannot explain the relative drop in water level for the chosen domains.

Calculations of water losses and gains from the Great Lakes system 
appear to balance (or nearly so) for most factors over the record length, which should lead to fairly stable water level over long periods of time. Over shorter timescales (2-5 years) precipitation trends may have an immediate signal seen in water levels, but over longer periods of time there was seemingly no accounting for the amount of water loss observed strictly dependent upon precipitation patterns. Hayhoe et al. [20] indicated a similar finding in describing a need for sustained changes in temperature (or precipitation) to drive water level trends. Only one remaining factor seems to act on longer time scales and has varied over the time series in a way that, could account for the extreme lows in water level, and that is of temperature increase.

As the only factor with no input counter-part to balance losses, we finally honed in on the air temperature and associated changes in evaporative loss versus water level time series. While Lenters et al. [21] indicated increased evaporation is driven by warmer water temperatures, our results seem to be able to link atmospheric temperature trends over long time scales to decreased water level (which would indicate enhanced evaporation), though if a robust data set could be obtained that allowed application of our EEMD analysis future work could include exploration of the role that winter time water temperature may play in enhancing evaporation. The results of the correlations showed promise as we find that air temperatures have risen significantly over the past 85 to 119 years. Calculated changes in evaporation that would accompany increased air temperatures appear to account for nearly all of the water loss that contributed to the low water levels observed throughout the Great Lakes in 2013. In fact, temperatures in the area were at their highest annual rates of rise coincident with water levels being in their highest rates of fall. The overall relationships suggest that for every rise in air temperatures of $0.1^{\circ} \mathrm{C}$, there will be a subsequent drop of water levels of $1.65 \mathrm{~cm}$; via enhanced evaporation of fresh lake waters. While these results may seem counterintuitive unless the same record lows are seen year-to-year, shorter time-scale weather patterns have a larger influence on shorter temporal (less than 7 years) periods of oscillation. Especially pronounced in the short-temporal scale variability is precipitation, which can vary by as much as $50.8 \mathrm{~cm} \mathrm{(20}$ in) in consecutive years. As such, variability in precipitation will have a strong effect on masking the underlying, long-term trends in water level that are related to rising temperatures and associated elevations in evaporation as revealed by our analyses.

It is of note that there have been several water level events since 2013 from which the long term losses of fresh water have undergone a change and the lakes have gained fresh water [22]. The headline on the front page of the April 2015 EOS was: "Great lakes water levels surge". The two-page article begins with the statement: "The recent 2-year surge represents one of the most rapid rates of water level change on the Great Lakes in recorded history and marks the end of an unprecedented period of low water levels". This presents an apparent quandary to our nearly 120 year, record length study which revealed downward trends in water levels. To wit, this recent upward movement begs the question: is the two-year change a precursor to increases in water levels or is it just a local blip? We maintain that short term, relatively large amplitude two year increases (or decreases in-kind) are just that: short term blips and non-representative of the multi-year to decadal to multi-decadal variability of Great Lakes water levels. It is a scientific disservice to water managers and to society to make these spurious claims, when the factors prove otherwise.

Of particular interest among the results were the observed, global connections between the long term trends modulated by a 110 year oscillation of air temperatures, even after ruling selectively minimizing urban heat effects, and water levels across the Great Lakes' domain and the global surface air temperature anomaly (GSTA) and the Atlantic Multi-decadal Oscillation (AMO) climate factor. This ties water level falling trends and long term variability directly to rising global temperatures and to GSTA and the AMO climate factors. We believe this is a significant finding regarding falling Great Lakes water levels and should provide important contributions to the debate about attribution of low lake levels.

Future Great lakes water level studies could expand upon the potential impacts of the findings within, might include the roles of evapotranspiration, surface water temperatures, water/air temperature gradients and the subsequent inquiry into where the "missing" water, which has, in effect, been removed from the system, might be found. For example, a total water balance study might reveal increased precipitation downstream, i.e. east, of the Great Lakes region. This is purely speculative at this time.

\section{Acknowledgement}

The authors acknowledge support from Coastal Carolina University for this study via the Burroughs \& Chapin Scholars Program; which is housed in the School of Coastal \& Marine System Science. Mr. James Epps generated the figures for this publication. Dr. John M. Zanetti provided a review of the paper. High performance computation facility at Coastal Carolina University and the Nationa Science Foundation's Extreme Science and Engineering Discovery Environment (XSEDE) computers were used for computation.

\section{References}

1. Gronewold AD, Fortin V, Lofgren B, Clites A, Stow CA (2013) Coasts Water Levels and Climate Change: A Great Lakes Perspective. Climatic Change 120: 697-711.

2. Chao P (1999) Great Lakes Water Resources: Climate Change Impact Analysis with Transient GCM Scenarios. Journal of American Water Resources Association 35: 1499-1507.

3. Mackay MD, Seglienieks F (2012) on the simulation of Laurentian Great Lakes water levels under projections of climatic change. Journal of Climatic Change.

4. Changnon Jr SA (1968) Precipitation Climatology of Lake Michigan Basin State of Illinois Public Document 17: 1-43.

5. Lofgren BM, Quinn FH, Clites AH, Assel RA, Eberhardt AJ et.al (2002) Evaluation of Potential Impacts on Great Lakes Water Resources Based on Climate Scenarios of Two GCMs. Journal Great Lakes Research 28: 537-554.

6. Lofgren BM, Hunter TS, Wilbarger J (2011) Effects of Using Air Temperature as a Proxy for Potential Evapotranspiration in Climate Change Scenarios of Great Lakes basin hydrology. Journal Great Lakes Research 37: 744-752.

7. Angel JR, Kunkel KE (2010) The Response of Great Lakes Water Levels to Future Climate Scenarios with an Emphasis on Lake Michigan-Huron. Journa Great Lakes Research 36: 51-58.

8. Huang NE, Shen Z, Long SR, Wu MC, Shih HH, et.al (1998) The empirical mode decomposition and the Hilbert spectrum for nonlinear and non-stationary time series analysis. Proceedings of the Royal Society of London A 454: 903995.

9. Wu Z, Huang NE (2009) Ensemble empirical mode decomposition: a noiseassisted data analysis method. Advanced Adaptation Data Analysis 1: 1-41.

10. Wu Z, Huang NE, Long SR, Peng CK (2007) On the Trend, Detrending and Variability of Nonlinear and Non-stationary Time Series. Proceedings of the National Academy of Science USA 104: 14889-14894.

11. Mainville A, Craymer MR (2005) Present-day tilting of the Great Lakes region based on water level gauges. GSA Bulletin 177: 1070-1080.

12. Fairall CW, Bradley EF, Rogers DP, Edson JB, Young GS (1996) Bulk parameterization of air-sea fluxes for Tropical Ocean-Global Atmosphere Coupled-Ocean Atmosphere Response Experiment. Journal of Geophysical Research 101: 3747-3764

13. International Joint Commission Commissioners (2000) Protection of the Waters of the Great Lakes: Final Report to the Governments of Canada and the United States. International Joint Commission. 
Citation: Pietrafesa LJ, Shaowu Bao, Huang NE, Gayes PT, Yan T, et al. (2016) Great Lakes Water Levels: Decomposing Time Series for Attribution. J Climatol Weather Forecasting 4: 153. doi:10.4172/2332-2594.1000153

14. Gronewold AD, Clites AH, Bruxer J, Kompoltowicz KW, Smith JP et.al (2015) Great Lakes water levels surge EOS 96: 14-17.

15. Mainville A, Forsberg R, Sideris MG (1992) Global Positioning System testing of geoids computed from geopotential models and local gravity data - A case study. Journal of Geophysical Research 97: 11137-11147.

16. Tushingham AM, Peltier WR (1991) Ice-3G: A new global model of late Pleistocene de-glaciation based upon geophysical predictions of post-glacial relative sea level change. Journal of Geophysical Research 96: 497-4523.

17. Peltier WR (1994) Ice Age Paleotopography. Science 265: 195-201.

18. Peltier WR (1995) VLBI baseline variations form the ice-4G model of postglacial rebound. Geophysical Research Letters 22: 465-468.
19. Peltier WR (2001) Global glacial isostatic adjustment and modern instrumental records of relative sea level history 75: 1-6.

20. Hayhoe K, VanDorn J, Croley T, Schlegal N, Wuebles D (2010) Regional Climate Change Projections for Chicago and the US Great Lakes. Journal Great Lakes Research 36: 7-21.

21. Lenters JD, Anderton JB, Blanken PD, Spence C, Suyker AE (2013) Assessing the Impacts of Climate Variabiliity and Change on Great Lakes Evaporation. The Climate Workspace 1-11.

22. Quinn F, The Potential Impacts of Climate Change on Great Lakes transportation. 